\title{
Gallbladder Torsion
}

\author{
Marilyn Wong, MBChB, Sandhya Pillai, MD \\ Department of General Surgery, North Shore Hospital, Waitemata District Health Board, Auckland, New Zealand \\ (both authors).
}

\begin{abstract}
Introduction: Gallbladder torsion is uncommon and difficult to diagnose before surgery.

Case description: We present a case of gallbladder torsion and review the literature on etiology, clinical presentation, radiological diagnosis, and intraoperative pitfalls.
\end{abstract}

Conclusion: A high index of suspicion for this rare entity and early surgical intervention are key in reducing mortality and preventing operative complications.

Key Words: Gallbladder, Laparoscopic cholecystectomy, Torsion abnormality.

\footnotetext{
Citation Wong M, Pillai S. Gallbladder Torsion: A Rare Diagnosis and Review of the Literature. CRSLS e2016.00079. DOI: 10.4293/CRSLS.2016.00079.

Copyright (C) 2016 by SLS, Society of Laparoendoscopic Surgeons. This is an open-access article distributed under the terms of the Creative Commons Attribution-Noncommercial-ShareAlike 3.0 Unported license, which permits unrestricted noncommercial use, distribution, and reproduction in any medium, provided the original author and source are credited.

Disclosures: none reported.

Address correspondence to: Marilyn Wong, MBChB, Department of General Surgery, North Shore Hospital, Shakespeare Road, Takapuna, Auckland 0622, New Zealand. Telephone: +642102464669, Fax: E-mail: Marilyn Wong. E-mail address: MarilynChiewLan.Wong@waitematadhb.govt.nz.
}

\section{INTRODUCTION}

Gallbladder torsion is where the gallbladder twists on its mesentery in the axis of the cystic artery and cystic duct. The first case was reported by Wendel in a 23-year-old woman in 1898. ${ }^{1}$ Approximately 500 cases have been published in the literature. ${ }^{3}$ It is often misdiagnosed before surgery. In this report, we present a case of gallbladder torsion with a review of the current literature.

\section{CASE DESCRIPTION}

An 82-year-old, slimly built, functionally independent woman presented with a 2-day history of right upper quadrant pain with clinical findings consistent with acute cholecystitis and a previous history of cholelithiasis. Her comorbidities included atrial fibrillation, for which she was on dabigatran.

Admission blood tests showed C-reactive protein (CRP) $<3 \mathrm{mg} / \mathrm{L}$, white blood cell (WBC) count $7.0 \times \mathrm{E}^{9} / \mathrm{L}$, and bilirubin of $9 \mu \mathrm{mol} / \mathrm{L}$. Ultrasonography revealed cholecystitis with a common bile duct (CBD) diameter of 8 $\mathrm{mm}$ and no choledocholithiasis. The patient was resuscitated with intravenous fluids and treated with intravenous antibiotics. Dabigatran was halted and she received bridging therapeutic heparin. Liver function test
(LFT) results became abnormal 5 days after admission. Bilirubin remained normal at $18 \mu \mathrm{mol} / \mathrm{L}$. Magnetic resonance cholangiopancreatography (MRCP) demonstrated marked gallbladder wall thickening of $13 \mathrm{~mm}$ and hemorrhage into the wall with suspicion of microperforation and a small pericholecystic collection. The patient remained afebrile and with minimal tenderness, no abdominal mass and a negative Murphy's test on examination. Based on her rising inflammatory markers (CRP 223) and MRCP findings, she proceeded to a laparoscopic cholecystectomy.

Intraoperative findings were of a very distended, thickwalled gallbladder with a $360^{\circ}$ clockwise torsion (Figure 1). The gallbladder was detorted by rotating anticlockwise $360^{\circ}$ (Figure 2). The thick-walled gallbladder was perforated with a pericholecystic fluid collection, contained by the adherent omentum and stomach. The gallbladder was attached by a narrow, short mesentery from Hartmann's pouch to just above the liver's edge (Figure 3). Rouviere's sulcus was identified closer to the liver's edge than usual (Figure 4). The cystic duct appeared short, and the CBD appeared tethered upward as a result of the unusual attachment of the gallbladder to the liver. Once the critical view was obtained, an intraoperative cholangiogram (IOC) 


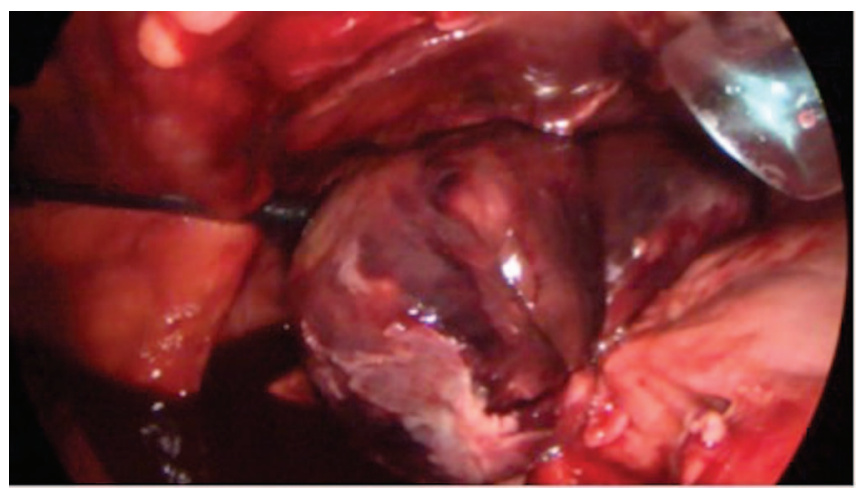

Figure 1. A $360^{\circ}$ clockwise torsion of the gallbladder.

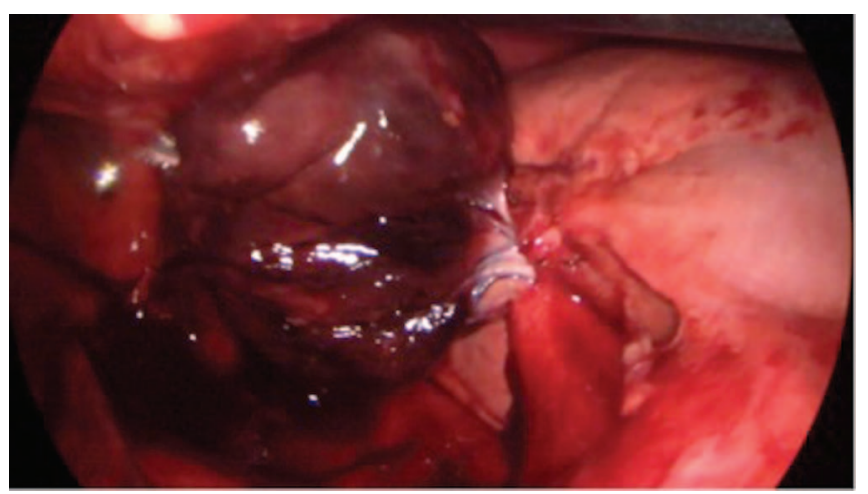

Figure 2. Partial anticlockwise detorsion of the gallbladder.

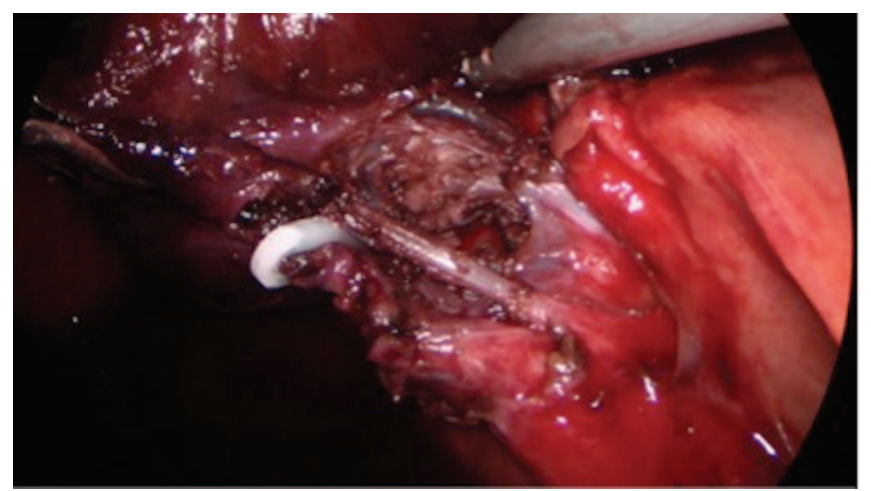

Figure 3. Short narrow mesentery from Hartmann's pouch to just below the liver's edge.

was performed that demonstrated a short cystic duct (Figure 5). The cholecystectomy stump was level with the liver's edge (Figure 4).

Histology showed a single calculus and hemorrhagic necrosis of the gallbladder, consistent with the history of torsion. On retrospective review of the ultrasonography, the torsion could not be identified on the preoperative image.

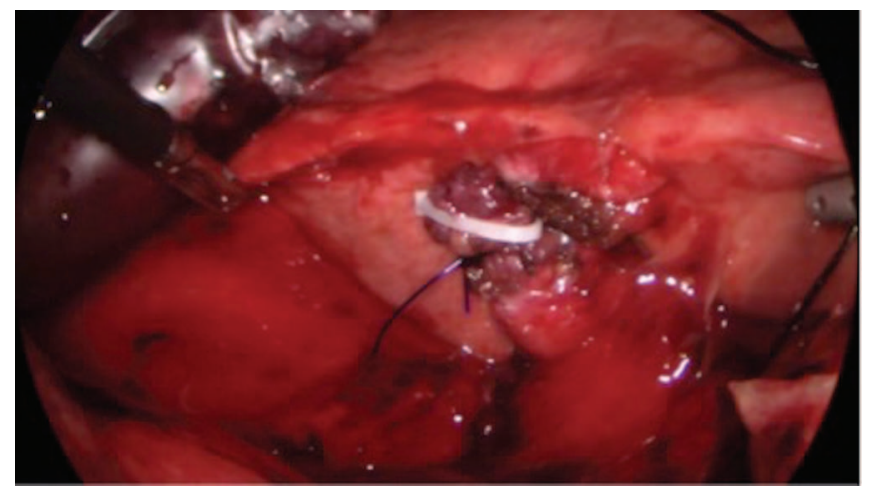

Figure 4. Cholecystectomy stump and Rouviere's sulcus close to the edge of the liver.

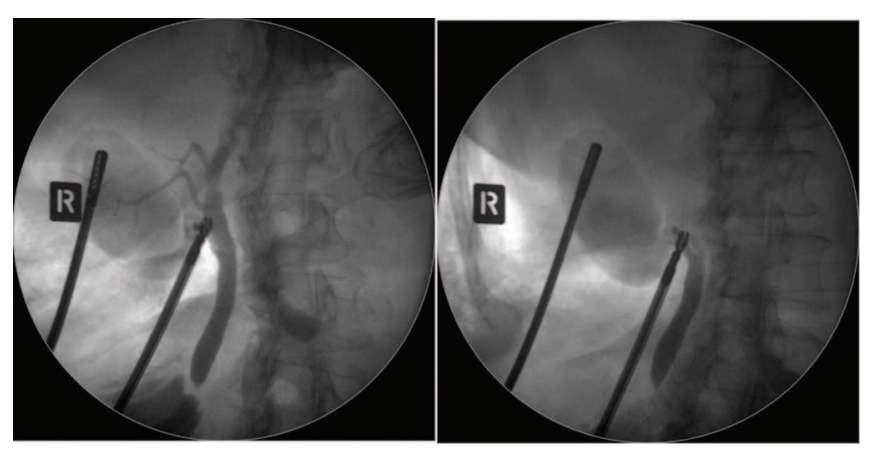

Figure 5. Intraoperative cholangiogram showing a short cystic duct.

The patient was discharged 3 days after surgery.

\section{DISCUSSION}

\section{Epidemiology}

Gallbladder torsion is a rare entity that is primarily found in elderly women, although even rarer pediatric cases have been reported in the literature. The estimated incidence is 1 in 365,520 hospital admissions ${ }^{2}$ with female:male ratios in the range of $3-4: 1^{3-5}$ in the adult population and $1: 2.5-4.0^{3,6}$ in the pediatric population. Gallbladder torsion has been reported in patients ranging from 2 to 100 years of age, with peaks seen in age groups $6-19$ and $60-80$ years $^{5}$ and a mortality rate of $6 \% .^{3}$

\section{Etiology}

The exact etiology is unknown. ${ }^{2-8}$ Two hypotheses of causation are abnormal anatomy involving a long or wide mesentery of the gallbladder vascular pedicle and a free-floating gallbladder predisposing the pedicle to torsion around its 
axis. Fat and liver atrophy with aging may result in gallbladder mesentery lengthening leading to a progressively mobile gallbladder. Rarer anatomical variants include torsion of the gallbladder fundus when not fixed to the gallbladder bed and a normally fixed gallbladder that is attached to a mobile segment of the liver, allowing torsion.

Kyphoscoliosis as a fulcrum for torsion, visceroptosis, malnutrition, adhesions, tortuous atherosclerotic cystic artery, violent peristalsis of neighboring organs, blunt abdominal trauma, the weight of the gallstones, and multiparity/ postpartum state have all been proposed as triggers. ${ }^{18}$ Gallstones do not appear to be a precipitating factor, given that gallbladder torsion is reported in about a quarter of patients and normal prevalence of gallstones in asymptomatic patients is $\sim 22 \%$.

\section{Clinical Diagnosis}

Between $9.8 \%$ and $26 \%$ of patients are reportedly diagnosed before surgery, despite advances in imaging modalities. ${ }^{3,7}$ Clinical presentation is nonspecific, even mimicking appendicitis ${ }^{7}$ and small bowel ischemia. ${ }^{10}$ Early diagnosis of the condition is imperative, to avoid the subsequent complications of gallbladder gangrene, perforation, and peritonitis. The "Triad of Triads" was developed by Lau in 1982 in an attempt to aid early preoperative diagnosis. Triad 1 described an elderly, thin patient with chronic chest or spinal deformity; Triad 2 described symptoms of sudden and early onset of symptoms of pain and vomiting with early presentation; Triad 3 described signs of a palpable right upper quadrant abdominal mass in a nontoxic or nonjaundiced patient and discrepancy between temperature and pulse.?

During surgery, gallbladder torsion can be complete $(>180$ degrees) or incomplete ( $<180$ degrees). Slightly more patients present with clockwise torsion (51-60\%).3,6

\section{Radiological Diagnosis}

Imaging findings are not specific. Ultrasound may reveal a thick-walled gallbladder, with or without cholelithiasis and with pericholecystic fluid. More specific signs of gallbladder torsion may be noted, such as gallbladder outside of its usual anatomical location with an echogenic conical structure (being the twisted pedicle) and positioned inferior to the liver or oriented transversely. ${ }^{11}$ Computed tomographic (CT) criteria suggested by Kitagawa et al. ${ }^{13}$ include fluid collection between gallbladder fossa and the gallbladder, the gallbladder in a horizontal axis, a well-enhanced cystic duct abnormally located to the right of the gallbladder, and a thickened gallbladder wall. ${ }^{13}$ Multidetector CT has been successful in diagnosing gallbladder torsion with reported findings of a twisted cystic artery with a "whirl sign" (only visible if the CT plane is perpendicular to the axis of the twisted gallbladder mesentery), V-shaped distortion of the extrahepatic ducts and distended gallbladder with wall hemorrhage. ${ }^{14,15}$ Magnetic resonance imaging (MRI) findings include $\mathrm{T}_{1}$-weighted hyperintensity of the gallbladder wall due to necrosis and hemorrhagia and may provide more information on the gallbladder neck in the form of a pulled up CBD near an undetected gallbladder neck. ${ }^{12}$ Hydroxyiminodiacetic acid (HIDA) scans are not commonly used in the acute setting for acute cholecystitis, but, in the case of gallbladder torsion, may add to preoperative diagnosis with findings of a "bull's eye" configuration because of the accumulation of radioactivity in the gallbladder. ${ }^{16}$

\section{Intraoperative Pitfalls}

Emergent surgical intervention with cholecystectomy is the required treatment of gallbladder torsion. Cholecystectomy may be performed via laparotomy or laparoscopy. The first reported laparoscopic cholecystectomy for gallbladder torsion was submitted in $1994 .{ }^{17}$ Principles to avoid bile duct injury in gallbladder torsion are identifying the gallbladder torsion, decompressing the gallbladder to allow grasping by instruments, derotating and identifying Calot's triangle, obtaining a critical view, performing an IOC for clear delineation of the anatomy and any associated anatomical variants, and then performing the cholecystectomy. ${ }^{18,19}$ As the torsion may have resulted in the CBD's being pulled or stretched up to the anterior edge of the liver, extra caution should be exercised during dissection to identify the cystic artery and cystic duct to avoid CBD injury. ${ }^{20}$

The reported incidence of morbidity caused by major bile injuries during cholecystectomy is on the order of $0.3-$ $0.5 \%{ }^{21,22,24}$ In cases such as in our patient, where there is distortion of the biliary anatomy, the use of an IOC would aid documentation and accurate identification of the cystic duct and biliary tree. In a study of 51,041 patients who underwent cholecystectomy pooled from the national Swedish Registry for Gallstone Surgery, a 1.5\% incidence of bile duct injury (BDI) was reported, in which intention to perform IOC was associated with reduced risk of BDI in patients with acute cholecystitis. ${ }^{24}$ Significant risk factors reported include severity of acute cholecystitis, open surgery, and a $>6$-day interval from admission to day of surgery. ${ }^{24,25}$

Percutaneous drainage via a cholecystostomy tube is a temporizing measure in patients in whom surgical intervention is deemed high-risk. In gallbladder torsion, drainage would only treat symptoms of distension but not progressive gallbladder ischemia, gangrene, and 
perforation. In patients who have had percutaneous cholecystostomy for presumed cholecystitis with no improvement, alternative diagnoses such as gallbladder torsion should be considered.

\section{CONCLUSION}

As gallbladder torsion is a rare entity, a high index of suspicion and early surgical intervention are key in reducing mortality and preventing operative complications.

\section{References:}

1. Wendel AV. A case of floating gallbladder and kidney complicated by cholelithiasis with perforation of the gallbladder. Ann Surg. 1898;27:199-202.

2. Janakan G, Ayantunde A, Hoque H. Acute gallbladder torsion: an unexpected intraoperative finding. World J Emerg Surg. 2008;3:9.

3. Reilly DJ, Kalogeropoulos G, Thiruchelvam D. Torsion of the gallbladder: a systematic review. HPB (Oxford). 2012;14: $669-672$.

4. Garciavilla PC, Alvarez JF, Uzqueda GV. Diagnosis and laparoscopic approach to gallbladder torsion and cholelithiasis. JSLS. 2010;14:147-151.

5. Boer J, Boerma Djamila, de Vries Reilingh TS. A gallbladder torsion presenting as acute cholecystitis in an elderly woman: a case report. J Med Case Rep. 2011;5:588.

6. Nakao A, Matsuda T, Funabiki S, et al. Gallbladder torsion: a case report and review of 245 cases reported in the Japanese literature. J Hepatobiliary Pancreat Surg. 1999;6:418-421.

7. Bauman Z, Ruggero J, Lim J. Gallbladder volvulus presenting as acute appendicitis. Case Rep Surg. 2015;2015:629129.

8. Mouawad NJ, Crofts B, Streu R, Desrochers R, Kimball BC. Acute gallbladder torsion: a continued pre-operative diagnostic dilemma. World J Emerg Surg. 2011;6:13.

9. Lau WY, Fan ST, Wong SH. Acute torsion of the gallbladder in the aged: a re-emphasis on clinical diagnosis. Aust NZ J Surg. 1982;52:492-494.

10. Vedanayagam MS, Nikolopoulos I, Janakan G, El-Gaddal A. Gallbladder volvulus: a case of mimicry. BMJ Case Rep. 2013; bcr2012007857.

11. Yeh HC, Weiss MF, Gerson CD. Torsion of the gallbladder: the ultrasonographic features. J Clin Ultrasound. 1989;17:123-125.

12. Fukuchi M, Nakazato K, Shoji H, Naitoh H, Kuwano H. Torsion of the gallbladder diagnosed by magnetic resonance cholangiopancreatography. Int Surg. 2012;97:235-238.
13. Kitagawa H, Nakada K, Enami T, et al. Two cases of torsion of the gallbladder diagnosed preoperatively. J Paediatr Surg. 1997;32:15671569.

14. Chou CT, Chen RC, Yang AD, Wu HK. Gallbladder torsion: preoperative diagnosis by MDCT. Abdom Imaging. 2007;32:657-659.

15. Tajima Y, Tsuneoka N, Kuroki T, Kanematsu T. Clinical images: gallbladder torsion showing a "whirl sign" on a multidetector computed tomography scan. Am J Surg. 2009;197:e9-e10.

16. Wang GJ, Colin M, Crossett J, Holmes RA. "Bulls-eye" image of gallbladder volvulus. Clin Nucl Med. 1987;12:231-232.

17. Schroder DM, Cusumano DA. III Laparoscopic cholecystectomy for gallbladder torsion. Surg Laparosc Endosc. 1995;5:330-334.

18. Hugh TB. New strategies to prevent laparoscopic bile duct injury: surgeons can learn from pilots. Surgery. 2002;132:826-835.

19. Buddingh KT, Weersma RK, Savenije RA, van Dam GM, Nieuwenhuijs VB. Lower rate of major bile duct injury and increased intraoperative management of common bile duct stones after implementation of routine intraoperative cholangiography. J Am Coll Surg. 2011;213:267-274.

20. Christoudias GC. Gallbladder volvulus with gangrene case report and review of the literature. JSLS. 1997;1:167-170.

21. Yegiyants S, Collins JC. Operative strategy can reduce the incidence of major bile duct injury in laparoscopic cholecystectomy. Am Surg. 2008;74:985-957.

22. Vettoretto N, Saronni C, Harbi A, Balestra L, Taglietti L, Giovanetti M. Critical view of safety during laparoscopic cholecystectomy. JSLS. 2011;15: 322-325.

23. Strasberg SM, Brunt LM. Rationale and use of the critical view of safety in laparoscopic cholecystectomy. J Am Coll Surg. 20101;211:132-138.

24. Törnqvist B, Strömberg C, Akre O, Enochsson L, Nilsson M. Selective intraoperative cholangiography and risk of bile duct injury during cholecystectomy. Br J Surg. 2015;102:952-958.

25. Törnqvist B, Waage A, Zheng Z, Ye W, Nilsson M. Severity of acute cholecystitis and risk of iatrogenic bile duct injury during cholecystectomy, a population based case-control study. World J Surg. 2016;40:1060-1067.

26. Strasberg SM, Hertl M, Soper NJ. An analysis of the problem of biliary injury during laparoscopic cholecystectomy. J Am Coll Surg. 1995;180:101-125.

27. Dahmane R, Morjane A, Starc A. Anatomy and surgical relevance of Rouviere's sulcus. Scientific World Journal. 2013;2013:254287.

28. Hugh TB, Kelly MD, Mekisic A. Rouviere's sulcus: a useful landmark in laparoscopic cholecystectomy. Br J Surg. 1997;84:1253-1254. 